\title{
Effects of small lesions in the globus pallidus on open-field and avoidance behavior in male and female rats
}

\author{
WILLIAM W. BEATTY and WILLIAM A. SIDERS \\ North Dakota State University, Fargo, North Dakota 58102
}

\begin{abstract}
Restricted lesions of the globus pallidus which did not cause aphagia or adipsia or affect open-field behavior in either sex retarded acquisition of two-way avoidance behavior by both male and female rats, but interfered with the development of one-way avoidance only by males. Sex differences in the behavioral effects of pallidal lesions differ from sex differences in the effects of striatal lesions and deficits in avoidance behaviors can be dissociated from impairments in consummatory activity that also may accompany basal ganglia damage.
\end{abstract}

Lénård, Sarkasian, and Szabo (1975) recently reported that fairly large lesions of the globus pallidus had markedly different effects on the duration of aphagia and adipsia in male and female rats. Despite intragastric feeding, most of their male subjects did not recover voluntary feeding and drinking and ultimately perished; the majority of females recovered ingestive behaviors and survived. In our laboratory we (Studelska \& Beatty, Note 1) have observed a sex difference in the effects of lesions of the ventral caudate on the acquisition of shuttlebox avoidance behavior. Males with such caudate lesions were severely impaired in this task, but females with similar lesions acquired avoidance behavior quite normally. The effects of the lesions were specific to the two-way avoidance task. Ventral caudate lesions had no effect on acquisition of one-way avoidance behavior or on activity and rearing in the open field in either sex.

Since histology revealed that the ventral caudate lesions often impinged upon the anterolateral portions of the globus pallidus, it seemed possible that the apparently sex-dependent effects of striatal damage were, in fact, caused by incidental damage to the globus pallidus. The present experiment examined that possibility.

\section{METHOD}

The animals were 18 male and 18 female rats of the Holtzman strain that had served in an experiment aimed at measuring shock thresholds prior to undergoing surgery in the present experiment. At about 140 days of age, half of the rats of each sex were assigned randomly to groups that received bilateral lesions of the globus pallidus (GP) or control procedures (sham operations or anesthetization). The lesions were produced by passing $1.5 \mathrm{~mA}$ dc between a brain anode (a No. 2 insect pin insulated except at the tip with Epoxylite) and a rectal cathode. General surgical procedures are described elsewhere (Bengelloun, Nelson, Zent, \& Beatty, 1976). With the rat's

Supported by PHS Grant HD 08206 from NICHHD. head held horizontally between bregma and lambda in a Kopf stereotaxic instrument, the coordinates with respect to bregma were: $.9 \mathrm{~mm}$ posterior, $2.7 \mathrm{~mm}$ lateral, and $5.5 \mathrm{~mm}$ beneath the cortex.

Behavioral tests began 2-3 weeks after surgery. Each rat was first tested for 2 consecutive days in an open-field apparatus (described in Bengelloun et al., 1976) for 9 min each day. On the next day, it was trained to a criterion of 10 consecutive avoidance responses in a one-way avoidance apparatus which consisted of a startbox with a grid floor and a safe chamber with a plastic floor suspended over a microswitch. The two compartments were separated by a guillotine door of opaque plastic. Raising the door activated a buzzer and $5 \mathrm{sec}$ later a $1.0-\mathrm{mA}$ shock was delivered to the grid floor from a GrasonStadler E700 source, unless the animal avoided by running to the safe compartment, terminating the buzzer and preventing delivery of shock. If the rat failed to avoid, both the buzzer and shock continued until it escaped to the safe compartment, terminating both buzzer and shock. The ITI varied between 10 and $20 \mathrm{sec}$, and the experimenter manually returned the rat to the startbox at the end of each trial. On the following day the rats were trained to the same criterion (10 consecutive avoidance responses) in shuttleboxes that are described elsewhere (Bengelloun et al., 1976). Five minutes after the rat was placed in the shuttlebox, escape-avoidance training began using the following parameters: CS-US interval, $10 \mathrm{sec}$; ITI, $60 \mathrm{sec}$; US intensity, $1.0 \mathrm{~mA}$. The CS (offset of light in the compartment occupied by the rat) and US overlapped and both were response terminated. On both avoidance tasks testing ended after 200 trials if the rat failed to meet criterion.

Following open-field and avoidance tests, we measured water consumption, both with unrestricted access to food and for $24 \mathrm{~h}$ without food. Water intake in response to an intraperitoneal injection of $1 \mathrm{M} \mathrm{NaCl}(20 \mathrm{ml} / \mathrm{kg})$ or physiological saline was also studied over a 6 -h period.

\section{RESULTS}

\section{Histology}

Figure 1 presents a reconstruction of a typical lesion at the point of maximum extent. Although at this locus (approximately the middle of the GP in terms of its anterior-posterior extent) destruction was typically quite extensive, damage to the more anterior and pos- 


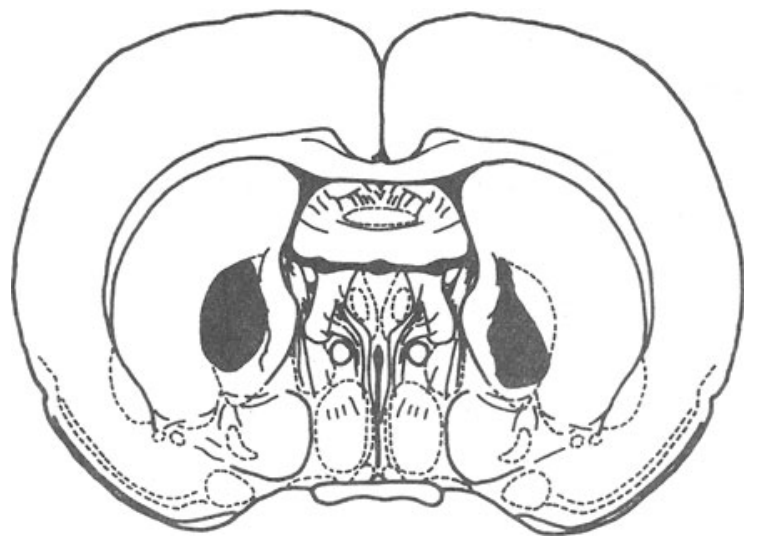

Figure 1. Reconstruction of a typical lesion at the point of maximum extent. The plate is Plate 24 from the atlas of Konnig and Klippel (1963).

terior areas of the pallidus was much less severe. Because the pallidus of the rat is located more laterally in its posterior portion than in its anterior region, the lesions usually damaged only the lateral part of the anterior pallidus and spared the posterior portion of the structure altogether. Anteriorly the lesions caused very minor damage to the ventral caudate and posteriorly they invaded the internal capsule and occasionally the reticular and lateral nuclei of the thalamus. No differences were detected in the size or locus of the lesions sustained by males and females.

\section{Consummatory Behavior}

The relatively small lesions used in the present study did not produce either aphagia or adipsia. Maintained on ordinary lab chow and tap water, all of the rats rapidly regained preoperative body weights. Subjects with lesions appeared to drink water from ordinary drinking tubes in a normal fashion. They did not display the bizarre drinking postures observed after larger pallidal lesions in other studies (e.g., Levine \& Schwartzbaum, 1973; Neill \& Linn, 1975). Water consumption in response to hypertonic saline injection was also unimpaired.

The ingestive behavior of rats with pallidal lesions differed from that of controls in two relatively minor ways: (1) Water intake was less than normal with food freely available $(p<.01)$, and $(2)$ in the absence of food, water intake was even more depressed. Controls drank about $50 \%$ of their normal intake when food was absent, while rats with pallidal lesions drank only $25 \%$ of their normal intake in the absence of food. This effect was also reliable $(p<.01)$. Despite these effects on water consumption, the consummatory behavior of the subjects with lesions was largely unimpaired and, except for the first few postoperative days, they maintained normal body weight levels throughout the experiments. No sex differences in the effects of the lesions on consummatory behaviors were observed.

\section{Open Field and Avoidance}

Performance during open-field and avoidance tests is shown in Table 1. Values for the number of squares entered and the number of rearing responses made are the mean number of responses per day. Pallidal lesions did not affect these measures of open-field behavior in either sex, but females reared more and entered more squares than males, as observed in many earlier studies.

Table 1 also describes avoidance behavior in terms of the number of escape responses made and trials required to meet the learning criterion. Globus pallidus lesions retarded the development of avoidance behavior on the one-way task by males $(\mathrm{p}<.02$ on both measures), but not by females. By contrast, pallidal lesions impaired acquisition by both sexes on the two-way task. An analysis of variance of the number of trials to criterion on the two-way task revealed significant main effects of lesion $[F(1,32)=6.40, p<.025]$ and sex $[F(1,32)=10.00, p<.01]$, but the Lesion by Sex interaction was not reliable $(\mathrm{F}=1.75)$. The pattern was generally similar for escapes, but only the sex difference was reliable $[\mathrm{F}(1,32)=6.83, \mathrm{p}<.025]$.

\section{DISCUSSION}

In our earlier work with ventral caudate lesions (Studelska \& Beatty, Note 1), we observed severely retarded acquisition of shuttlebox avoidance behavior, but only in male rats. The same animals learned one-way avoidance normally using exactly the same task as used in the present study. Females with similar ventral caudate lesions avoided normally on both the one-way and two-way tasks. These striatal lesions produced transient aphagia and adipsia, and prandial drinking in both sexes, but had no effect on open-field behavior in either sex. Because Lénárd et al. (1975) observed a large sex difference in the effects of pallidal lesions on feeding and drinking, we suspected that the sex difference we had observed in the effect of ventral caudate lesions on shuttlebox avoidance behavior might have been caused by incidental damage to the globus pallidus. The present data indicate that explanation is probably incorrect.

Instead, it appears that, while both striatal and pallidal lesions are more likely to impair behavior in males than in females, the specific behaviors affected by the lesions in a sex-dependent fashion are different. Furthermore, the present findings clearly demonstrate that the deficits in avoidance behavior arising from basal ganglia damage can occur when other motor and consummatory functions are largely unimpaired.

Table 1

Mean Performance

\begin{tabular}{lcccccr}
\hline & \multicolumn{2}{c}{ Open Field } & \multicolumn{2}{c}{ One-Way } & \multicolumn{2}{c}{ Two-Way } \\
& Squares & Rears & Escapes & Trials & Escapes & Trials \\
\hline Male-GP & 112.0 & 15.8 & 37.6 & 58.0 & 120.3 & 172.4 \\
Male-C & 108.6 & 23.8 & 4.7 & 17.2 & 72.3 & 102.1 \\
Female-GP & 232.3 & 49.7 & 4.7 & 17.1 & 54.3 & 90.6 \\
Female-C & 196.1 & 49.7 & 3.8 & 16.3 & 45.8 & 68.6 \\
\hline
\end{tabular}

Note $-G P=$ globus pallidus, $C=$ control .

\section{REFERENCE NOTE}

1. Studelska, D. R., \& Beatty, W. W. Sex differences in the effects of neostriatal lesions on open-field and avoidance 
behavior in rats. Paper presented at the annual meeting of the Eastern Conference on Reproductive Behavior, Saratoga Springs, New York, June 1976.

\section{REFERENCES}

Bengelloun, W. A., Nelson, D. J., Zent, H. M., \& BeatTy, W. W. Behavior of male and female rats with septal lesions: Influence of prior gonadectomy. Physiology and Behavior, 1976, 16, 317-330.

KönIG, J. F. R., \& KLIPPEL, R. A. The rat brain: A stereotaxic atlas. Baltimore: Williams \& Wilkins, 1963.

LÉNÁRD, L., Sarkasian, J., \& Szabo, I. Sex-dependent survival of rats after bilateral pallidal lesions. Physiology and Behavior, 1975, 15, 389-397.

Levine, M. S., \& Schwartzbaum, J. S. Sensorimotor functions of the striatopallidal system and lateral hypothalamus and consummatory behavior in rats. Journal of Comparative and Physiological Psychology, 1973, 85, 615-635.

NeILl, D. B., \& LiNN, C. L. Deficits in consummatory responses to regulatory challenges following basal ganglia lesions in rats. Physiology and Behavior, 1975, 14, 617-624.

(Received for publication March 21, 1977.) 